\title{
Screening for COVID-19 Risk Using VIEW (COVID-19 Early Warning) System
}

\author{
Shardul Joshi, Gajanan Sakhare ${ }^{1}$, Aditi R. Pais ${ }^{2}$ \\ Chief Technology Officer, Division of Respiratory Health, Department of Research and Development, ${ }^{1}$ Managing Director, ${ }^{2}$ Chief Executive Officer, \\ Briota Technologies Private Limited, Pune, Maharashtra, India
}

\section{Abstract}

Background: As COVID-19 continues to spread globally, a safe workforce reentry for people with elevated individual and occupational risk from COVID-19 is essential. Risk stratification may help to identify individuals with COVID-19 risk levels and take appropriate measures. Objectives: (a) To reduce the burden of (COVID-19 among) corporate health-care ecosystem by multiple layers of screening of employees and their families through Nurse Education Health Assistants (NEHA) mobile application and using VIEW (COVID-19 Early Warning System) scores. (b) To offer teleconsultation services to individuals with the assistance of doctors and NEHA coaches (c) To assess accuracy/efficacy of VIEW system. Materials and Methods: A cross-sectional survey using NEHA mobile application was conducted among 2424 employees and their families of a leading multinational company. The human resource staff of the company collected data using NEHA application and uploaded it through a web portal. Further investigation was carried out by NEHA coaches through telephonic consultation using VIEW data. Results: More than half of the participants received the same VIEW scores by system and doctor zone, i.e., A VIEW score (58.54\%), B VIEW score (59.63\%), and C VIEW score (66.67\%). System zone of VIEW system was compatible to categorize participants depending upon the level of risk probability toward COVID-19. Furthermore, NEHA coach and doctor gave the same VIEW scores under A (81.74\%), $\mathrm{B}(67.63 \%)$, and C (38.46\%). Conclusion: VIEW system is useful to detect risk probability toward COVID-19 infection and stratify patients under different VIEW zones to prioritize medical care, identify isolation needs, identify hospitalization needs at a scale.

Keywords: COVID-19 risk, NEHA coaches, screening, VIEW zone

\section{INTRODUCTION}

COVID-19 has imposed a severe threat to entire mankind. The deadly disease has already claimed almost three million lives so far and is rampantly spreading across the world posing immense challenge to economic, social, health-care dimensions of the human beings. ${ }^{[1]}$ Although efforts are being undertaken by nations across the globe to curb the infection, overwhelming number of deaths have questioned the efficiency of most of the developed nations across the world. The low- and middle-income countries are the most targeted economies during the era of the pandemic. The catastrophic health-care expenditures have put many countries to the edge of poverty. ${ }^{[2]}$ Countries across the globe are struggling to slow down the rate of transmission by increased test and treatment, contact tracing the suspected cases and quarantining, restricting the mass gathering,

\begin{tabular}{|l|l|}
\hline \multicolumn{3}{|c|}{ Access this article online } \\
\hline Quick Response Code: & Website: \\
\hline & www.ijrc.in \\
\cline { 2 - 2 } & \\
\hline
\end{tabular}

adopting measures such as partial or complete lockdown, mask campaigns and by maintaining social distancing and ensuring hand hygiene. ${ }^{[3]}$

This new normal has also persuaded the industries across the globe to ensure safe and nonhazardous workplace for its employees. According to guidelines recommended by the Center for Disease Control and Prevention, companies should conduct a hazard assessment to avoid potential spread of COVID-19 infection. They should ensure adequate ventilation in the building by opening doors and windows,

Address for correspondence: Mr. Shardul Joshi, Chief Technology Officer, Briota Technologies Private Limited, Plot No. 3A, Anjali Bungalow, Near Vikhe Patil School, Krushi Housing Society, Pune - 411 016, Maharashtra, India. E-mail: shardul@briota.co

This is an open access journal, and articles are distributed under the terms of the Creative Commons Attribution-NonCommercial-ShareAlike 4.0 License, which allows others to remix, tweak, and build upon the work non-commercially, as long as appropriate credit is given and the new creations are licensed under the identical terms.

For reprints contact: WKHLRPMedknow_reprints@wolterskluwer.com

How to cite this article: Joshi S, Sakhare G, Pais AR. Screening for COVID-19 risk using VIEW (COVID-19 early warning) system. Indian J Respir Care 2021;10:206-12.

Received: $01-12-2020$

Revised: $15-05-2021$

Accepted: 16-05-2021 
practice at least 6 feet social distancing, and follow safety practices (handwashing, wearing personal protective equipment) to cut-down viral spread. ${ }^{[4]}$ The transmission of COVID-19 has resulted in increased anxiety and stress among workers. ${ }^{[5]}$ Adequate support system should be made available to the individuals to identify potentials threats to mental health. Access to authentic information and nonstigmatized environment can narrow the barriers in safeguarding mental health at occupational settings. Workplaces should come up with individual action plans to prevent and mitigate COVID-19 and must review those action plans on a regular basis to ensure compliance. Many companies are conducting routine thermal screening for COVID-19 and monitoring vital parameters to identify the potential risk. In addition to screening, enhanced health awareness has been provided to follow healthy practices within the work environment and outside. ${ }^{[6]}$

VIEW (COVID-19 Early Warning System) is a system used for stratification of patients based on VIEW score calculation. This is done using machine learning algorithms using dataset which consists of vital parameters, medical conditions history, and COVID-19 test result. This VIEW score is calculated on mobile application called "NEHA" and it can be viewed on VIEW Portal/Dashboard by medical authority.

The current survey was undertaken with a purpose to screen the individuals for COVID-19 risk using VIEW system, so as to provide appropriate referrals to seek early medical interventions. The results of this study are crucial to construct innovative ideas to comply with pandemic risk detection and control.

\section{Materials And Methods}

A total of 2424 employees of a leading multinational company in Hirakud, Utkal, Odisha, India, in steel and ore manufacturing and their families were screened for COVID-19 risk from September 9, 2020, to September 19, 2020. Protocol of this study was approved by Human Resource department of leading multinational company. Written consent was taken from all participants and they were informed about study objectives. A cross-sectional study design was used for screening the participants, and purposive sampling technique was used to select the participants. The inclusion criteria were employees of multinational company in steel and ore manufacturing and their families who were willing to participate for the screening of COVID-19 risk.

The data were captured by the human resource staff of the same multinational company using "NEHA," Apps, Health and Fitness, BRIOTA Technologies Private Limited, Google Play Store, an android mobile application for feasible and hassle-free data collection.

A questionnaire consisting of WHO risk assessment checklist was confirmed by a pulmonary medical expert for initial assessment by human resource staff [Figure 1]..$^{[7]}$ Data obtained was filled into Nurse
Education Health Assistants (NEHA) mobile application and then transferred to the cloud server.

The first level of patient stratification was autogenerated based on the VIEW score that was calculated by the VIEW machine learning algorithm [Table 1]. Dataset used for machine learning included temperature reading, COVID-19 status, symptoms,

\begin{tabular}{|c|c|c|}
\hline \multirow{2}{*}{$\begin{array}{l}\text { VIEW zone } \\
\text { marking }\end{array}$} & \multicolumn{2}{|c|}{ Score, range (indicative) } \\
\hline & Minimum & Maximum \\
\hline Zone E & 161 & 300 \\
\hline Zone D & 121 & 160 \\
\hline Zone $\mathrm{C}$ & 80 & 120 \\
\hline Zone B & 40 & 79 \\
\hline Zone A & 0 & 39 \\
\hline
\end{tabular}

Table 2: Demographic and health variables $(n=2166)$

\begin{tabular}{lc}
\hline Variables & $\boldsymbol{n}(\%)$ \\
\hline Demographic variables & \\
Age (years) & $1119(51.7)$ \\
$\leq 30$ & $873(40.3)$ \\
$31-50$ & $174(8)$ \\
$\geq 50$ & 27.68 \\
Mean age (years) & \\
Gender & $1158(53.5)$ \\
Male & $1008(46.5)$ \\
Female & \\
Health variables & \\
Temperature & $117(5.4)$ \\
Not recorded & $1449(66.9)$ \\
Normal & $596(27.5)$ \\
Below $100^{\circ} \mathrm{F}$ & $4(0.2)$ \\
Above $100^{\circ} \mathrm{F}$ & \\
SpO & $185(8.5)$ \\
Not recorded & $1880(86.8)$ \\
Normal $(\geq 95 \%)$ & $101(4.7)$ \\
Below $(<95 \%)$ & \\
COVID-19 test status & $2072(95.7)$ \\
Test not done & $13(0.6)$ \\
Positive & $81(3.7)$ \\
Negative & \\
Symptoms & \\
No symptoms & $18(0.8)$ \\
Cough & $2134(98.5)$ \\
Others & $18(0.8)$ \\
Comorbidity status & $14(0.6)$ \\
None & \\
HTN & \\
DM & $41(1.9)$ \\
HTN and DM & $46(2.1)$ \\
Asthma & \\
Thyroid abnormalities & \\
\hline : Oxygen saturation, HTN: Hypertension, DM: Diabetes & mellitus \\
&
\end{tabular}




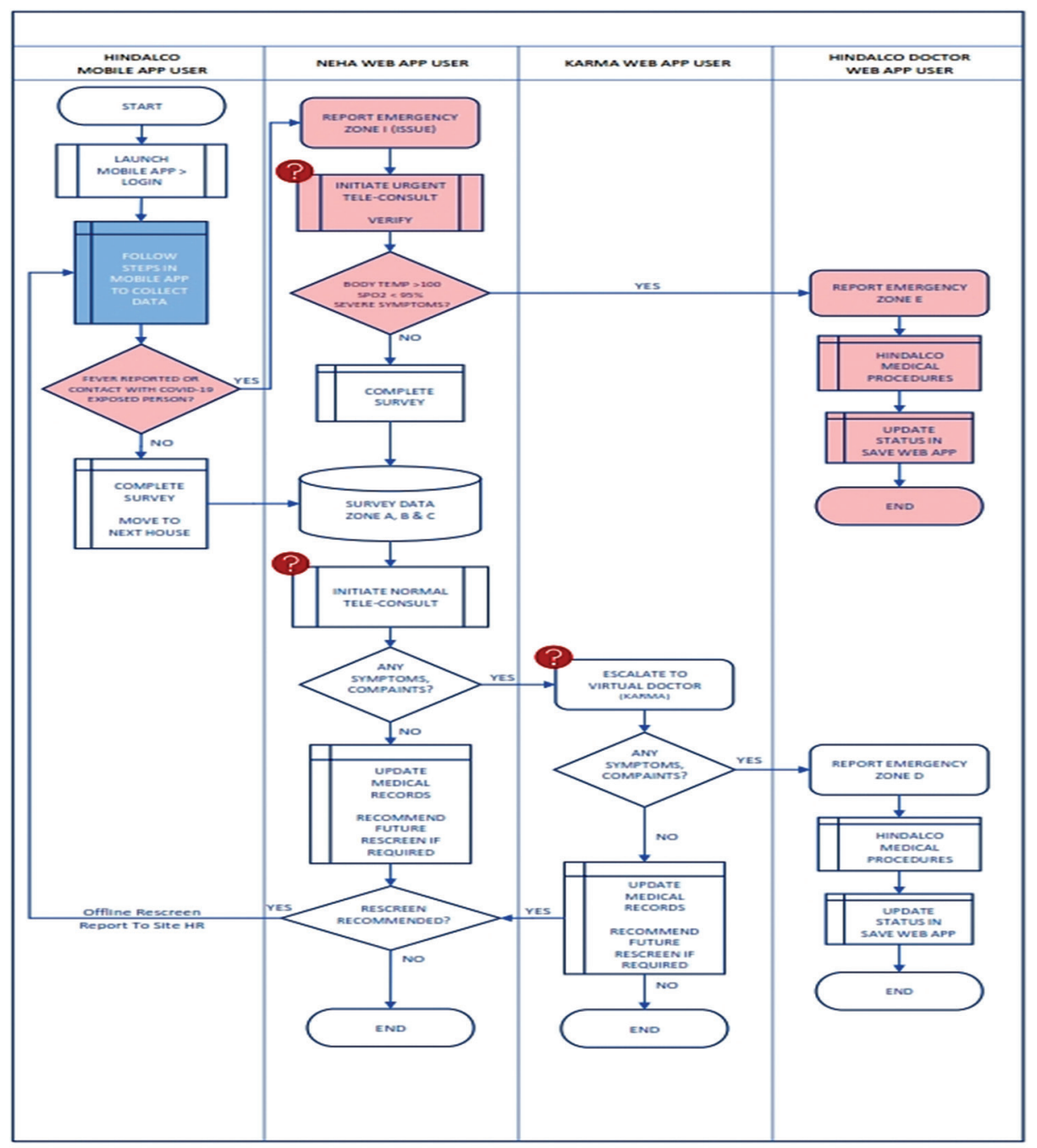

Figure 1: Flow chart to show the process of screening

oxygen saturation as read by pulse oximeter $\left(\mathrm{SpO}_{2}\right)$ level, medical condition such as asthma, Chronic Obstructive Pulmonary Disease (COPD), and hypertension as shown in Table 2.

Example of machine learning algorithm for calculation of system VIEW score using linear regression analysis:

VIEW Score $=a^{*}($ Temperature $)+b^{*}\left(\mathrm{SpO}_{2}\right.$ concentration $)+c^{*}$ (Symptoms) $+\mathrm{d} *($ Medical condition $)+\mathrm{e}^{*}($ COVID-19 status $)+\mathrm{f}$

i.e., a, b, c, d, e, f are coefficients and constant derived using training dataset of participants.

The following methodology was used for NEHA and doctor coaches for assigning VIEW zones:

VIEW Zone A: "A" VIEW score is given for person with very low risk such as having no symptoms or with or without comorbidity (but under control).

VIEW Zone B: "B" VIEW score is given for person with low risk such as having mild symptoms or with comorbidity.
VIEW Zone C: "C" VIEW score is given for person with moderate symptoms or with more than one comorbidity or has recently recovered from COVID-19.

VIEW Zone D: "D" VIEW score is given only by doctors onboard for person with severe symptoms, with comorbidities and recently came in contact with COVID-19 positive case.

VIEW Zone E: "E" VIEW score is given only by human resource staff and NEHA coach for person with severe symptoms, with comorbidities or showing $\mathrm{SpO}_{2}<95 \%$ and recently came in contact with a COVID-19 positive case.

Based on this initial patient stratification done by the system, NEHA coaches (Certified Nurses and Certified Respiratory Therapists-health-care professionals with qualified degree, also known as "NEHAs"). They provided telephonic consultation to the participants of survey and escalated the emergency cases to either onsite medical team or doctors depending upon the level of risk.

They carried out further investigation through telephonic consultation either by audio or video calls. High-risk cases 
marked as emergency in the NEHA mobile application were further handled by NEHA coach on high priority. In the current survey, BRIOTA technologies had qualified physicians on board to provide virtual consultation to the participants. Cases that needed immediate attention were escalated to on site medical team and cases which had moderate risk were escalated to these doctors on board by the NEHA coach.

NEHA coach was also allowed to do changes in patient stratification based on their consultation and observation of a patient. Permission was taken from multinational company to have access to the records of their employees maintained in the register. The contact details were obtained, and the participants were being contacted over the phone or in-person at their households. Participation was voluntary and oral consent was obtained from all the participants after the purpose of the study was explained to them using a participant information sheet. Confidentiality of the data was guaranteed.

\section{Data analysis}

The data analysis was performed using Statistical Package for the Social Sciences 20 (SPSS 20-IBM Corp. Released 2011. IBM SPSS Statistics for Windows, Version 20.0. Armonk, NY: IBM Corp) software and Microsoft Excel (Microsoft Corporation; Albuquerque, New Mexico, United States, statistics was reporting Excel). Descriptive statistics were used for reporting demographic data and health data. Categorization of VIEW scores was done using Microsoft Excel [Figure 2].

\section{RESULTS}

Of 2166 participants in the survey, $51.7 \%$ were under 30 years of age [Table 2]. Mean age of the participants was 27.68 years. About $53.5 \%$ of individuals were male. Temperature above $100^{\circ} \mathrm{F}$ was recorded among 4 participants, and pulse

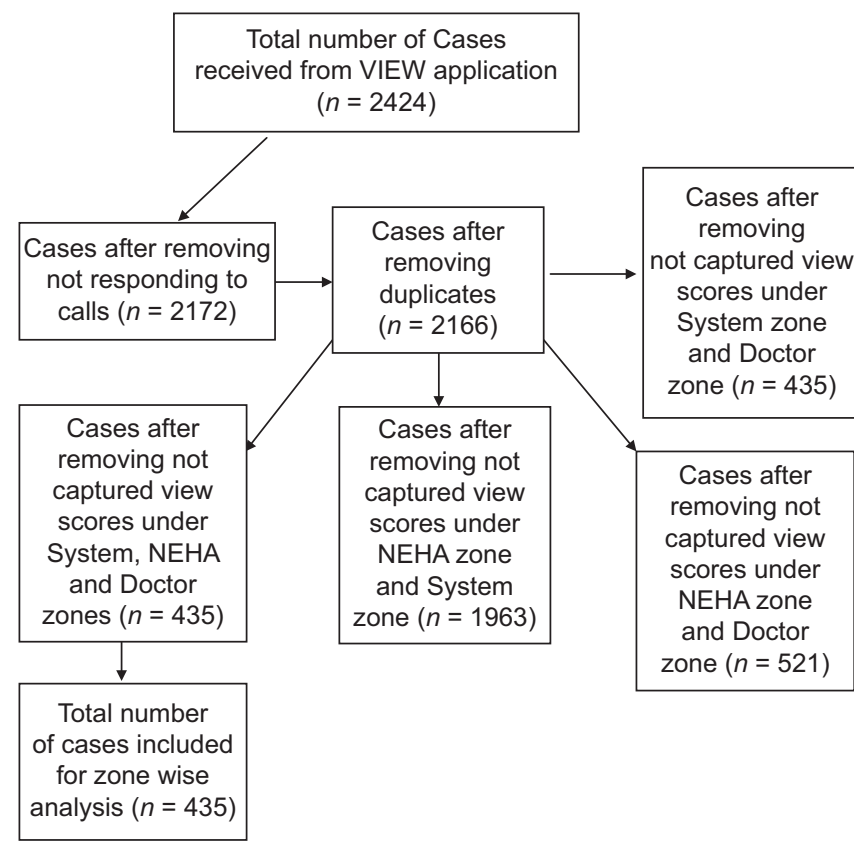

Figure 2: Flow chart showing inclusion of participants for data analysis oximetry $\left(\mathrm{SpO}_{2}\right)$ below $95 \%$ was reported in 101 participants. 94 participants revealed that they have undergone COVID-19 testing and 13 of them reported testing positive for COVID.

Zone-wise distribution of cases was done to classify individuals depending upon the level of risk [Table 3]. According to the severity, the individuals were classified under VIEW scores A, B, C, E, and D by the System, NEHA Coach, and Doctor (A - very low risk, $\mathrm{B}$ - low risk, $\mathrm{C}$ - medium risk, $\mathrm{E}-\mathrm{E}$ view score was given by system or NEHA in case of emergency which needs immediate action). D view score was given by doctor so that site medical team can do further assessment.

Followed by initial screening by human resource staff, the system captured $60.94 \%$ of participants under A VIEW score whereas NEHA coach captured $90.67 \%$ of participants under A VIEW score through teleconsultation. The system did not assign VIEW scores to 202 individuals (9.3\%) of participants as they were not available in the household during the time of survey. Therefore, NEHA coaches have captured the details of these participants through teleconsultation.

The VIEW scores of system and doctor matching for the same respondent have been shown in Table 4. This table shows that more than half of the participants were given the same VIEW scores by system and doctor. NEHA coach and doctor gave the same A and B VIEW scores for $>50 \%$ of participants.

Table 5 shows the conversion of VIEW scores of System by NEHA Coach zone. NEHA Coach converted majority of A, B, C, E VIEW scores of system zone under A zone. The variations in system and NEHA Coach VIEW scores for the same participants were because of identification of susceptible cases (those who recently traveled outside state, those who came in contact with COVID-19-positive cases) by human resource staff and they were given B, C, E VIEW scores by system. Later, NEHA Coach gave them A VIEW scores after in depth investigation as they had no symptoms and tested negative for COVID-19.

The system either scored the same or slightly higher (worse) suggesting a more cautious approach. $1278(65.1 \%)$ people were scored the same by both methods, whereas $478(22.06 \%)$ were scored one level worse and $112(5.17 \%)$ by two levels by the System as compared to NEHA coach. Only $8(0.37 \%)$ out of 2166 individuals were scored lower (erroneously considered better) by one or two levels by the System as compared to NEHA. Thus, although Kappa statistics $(\kappa=0.037)$ could not show any agreement between the system scoring and NEHA scoring, the variability pertained mainly to "no risk" or "low risk" categories (for reasons mentioned above).

Similar pattern was seen when the scores given by system and the doctor were compared. Table 6 shows that even the participants under A and B VIEW scores had been escalated to doctors though they had no symptoms or comorbidity. This was done when participants asked for escalation as they were anxious about the current situation or they wanted to know more about precautionary measures. Only one person out of the 
Table 3: Zone-wise distribution of 2166 participants as assessed by the system, Nurse Education Health Assistants coach and the doctor, $\boldsymbol{n}(\%)$

\begin{tabular}{|c|c|c|c|c|c|c|}
\hline Zones & A VIEW score & B VIEW score & C VIEW score & D VIEW score & E VIEW score & Not assigned \\
\hline System zone & $1320(60.94)$ & $483(22.3)$ & $140(6.46)$ & - & $21(0.97)$ & $202(9.33)$ \\
\hline NEHA coach zone & 1964 (90.67) & $174(8.03)$ & $13(0.6)$ & - & $14(0.65)$ & $1(0.05)$ \\
\hline Doctor zone & 367 (16.94) & $139(6.42)$ & $13(0.6)$ & $2(0.09)$ & - & $1645(75.95)$ \\
\hline
\end{tabular}

NEHA: Nurse Education Health Assistants

\begin{tabular}{|c|c|c|}
\hline \multicolumn{3}{|c|}{$\begin{array}{l}\text { Table 4: Same VIEW scores captured by different zones, } \\
n(\%)\end{array}$} \\
\hline $\begin{array}{l}\text { VIEW } \\
\text { scores }\end{array}$ & $\begin{array}{l}\text { Same VIEW scores } \\
\text { captured by system and } \\
\text { doctor }(n=256), n(\%)\end{array}$ & $\begin{array}{c}\text { Same VIEW scores } \\
\text { captured by NEHA coach } \\
\text { and doctor }(n=399), n(\%)\end{array}$ \\
\hline $\mathrm{A}$ & $185(72.26)$ & $300(75.18)$ \\
\hline B & $65(25.39)$ & $94(23.55)$ \\
\hline $\mathrm{C}$ & $6(2.34)$ & $5(1.25)$ \\
\hline
\end{tabular}

NEHA: Nurse Education Health Assistants

\begin{tabular}{|c|c|c|c|c|}
\hline \multirow{2}{*}{$\begin{array}{l}\text { System zone } \\
\text { VIEW scores }\end{array}$} & \multicolumn{4}{|c|}{ NEHA coach zone VIEW scores, $n$ (\%) } \\
\hline & A & B & C & Total \\
\hline A & 1240 & 74 & 6 & 1320 \\
\hline B & 445 & 36 & 2 & 483 \\
\hline $\mathrm{C}$ & 105 & 32 & 2 & 139 \\
\hline E & 13 & 7 & 1 & 21 \\
\hline Total & 1803 & 149 & 11 & 1963 \\
\hline
\end{tabular}

$\kappa=0.037$, (95\% CI: 0.0076-0.066), $P<0.01$. NEHA: Nurse Education

Health Assistants, CI: Confidence interval

Table 6: Distribution of VIEW scores by system and doctor $(n)$

\begin{tabular}{|c|c|c|c|c|c|}
\hline \multirow{2}{*}{$\begin{array}{l}\text { System zone } \\
\text { VIEW scores }\end{array}$} & \multicolumn{4}{|c|}{ Doctor zone VIEW scores } & \multirow[t]{2}{*}{ Total } \\
\hline & $A$ & B & C & D & \\
\hline A & 185 & 65 & 6 & - & 256 \\
\hline B & 84 & 30 & 1 & - & 115 \\
\hline $\mathrm{C}$ & 36 & 13 & 1 & 1 & 51 \\
\hline $\mathrm{E}$ & 11 & 1 & 1 & - & 13 \\
\hline Total & 316 & 109 & 9 & 1 & 435 \\
\hline
\end{tabular}

К $=0.008$, CI: $-0.064-0.080$. CI: Confidence interval

$447(0.22 \%)$ was scored "B" (mild symptoms) by the system but was categorized into "C" (moderate symptoms) by the doctor.

When the scores given by NEHAand the doctor were compared, there was a moderate agreement between them $(\kappa=0.564[95 \%$ confidence interval, 0.479-0.648], $P=0.000$ ).

Table 7 shows the VIEW scores of System scores converted by NEHA Coach and doctor zone. The conversion was mostly down gradation by both NEHA coach and the doctor (considered less severe than that assessed by the System). Majority of the participants were given System and
NEHA Coach.

System zone did not give any VIEW scores to 202 cases since the human resource staff did not do screening because of COVID threat. NEHA Coach stratified them [Table 8]. Fourteen of these 202 people had recently contacted COVID-positive cases and were having symptoms and NEHA coach gave them emergency VIEW score E. Doctor zone reassessed them and gave VIEW scores A, B, D to them based on COVID risk [Table 9]. Eighty-six cases that were not assigned by the system were also seen and stratified by the doctor [Table 10].

\section{Discussion}

The novelty of this pandemic, along with its uncertainties, made it critical for health authorities to plan appropriate strategies to prepare and manage the public. ${ }^{[8]}$ It is of utmost importance that the speed with which COVID-19 is spreading across the world calls for rapid screening of the individuals to prevent the spread of infection. Several precautionary measures in the wake of the pandemic caused restricted entry of employees in most of the companies. ${ }^{[9]}$

This study was done to screen the employees and their families for COVID-19 risk by grouping individuals according to their severity based on VIEW scores and to offer teleconsultation services to the individuals with the assistance of doctors and NEHA coach (NEHAs) on board.

In Wuhan, China, the most common symptoms detected from the onset of this outbreak included fever, cough, and fatigue. ${ }^{[10]} \mathrm{A}$ cross-sectional study was done among health-care workers revealed that most common complaints reported were exhaustion, muscle pain, dysgeusia, and anosmia. ${ }^{[11]}$ In our study, 5-10 participants had such symptoms and they were referred to on-site medical team and onboard doctors for further investigation and immediate action.

Researchers have revealed that people with noncommunicable diseases such as diabetes, cancer, respiratory diseases (COPD, asthma), and cardiovascular diseases are more vulnerable for COVID-19 as they have higher chance of contracting the disease. Mortality rates are higher among those individuals. ${ }^{[12,13]}$ Moreover, elderly with comorbidities are at greater risk of evolving severe illness and at an increased risk of death if they contract COVID-19 infection. ${ }^{[14-16]}$ In the current survey, $6.1 \%$ of participants had comorbidities and they were escalated to onboard doctors of BRIOTA for teleconsultation to make sure they get proper medical interventions. 


\begin{tabular}{|c|c|c|}
\hline $\begin{array}{l}\text { System zone } \\
\text { VIEW scores }\end{array}$ & $\begin{array}{l}\text { NEHA coach zone } \\
\text { VIEW scores, } \boldsymbol{n}(\%)\end{array}$ & $\begin{array}{l}\text { Doctor zone VIEW } \\
\text { scores, } n(\%)\end{array}$ \\
\hline \multicolumn{3}{|l|}{ A } \\
\hline A & $187(73.05)$ & $185(72.27)$ \\
\hline B & 65 (25.39) & 65 (25.39) \\
\hline $\mathrm{C}$ & $4(1.56)$ & $6(2.34)$ \\
\hline Total & $256(100)$ & $256(100)$ \\
\hline \multicolumn{3}{|l|}{$\mathrm{B}$} \\
\hline $\mathrm{A}$ & $78(67.83)$ & $84(73.04)$ \\
\hline $\mathrm{B}$ & $35(30.43)$ & $30(26.09)$ \\
\hline $\mathrm{C}$ & $2(1.74)$ & $1(0.87)$ \\
\hline Total & $115(100)$ & $115(100)$ \\
\hline \multicolumn{3}{|l|}{$\mathrm{C}$} \\
\hline A & $20(39.22)$ & $36(70.59)$ \\
\hline B & $29(56.86)$ & $13(25.49)$ \\
\hline $\mathrm{C}$ & $2(3.92)$ & $1(1.96)$ \\
\hline $\mathrm{D}$ & - & $1(1.96)$ \\
\hline Total & $51(100)$ & $51(100)$ \\
\hline \multicolumn{3}{|l|}{$\mathrm{E}$} \\
\hline $\mathrm{A}$ & $6(46.15)$ & $11(84.62)$ \\
\hline B & $6(46.15)$ & $1(7.69)$ \\
\hline $\mathrm{C}$ & $1(7.69)$ & $1(7.69)$ \\
\hline Total & $13(100)$ & $13(100)$ \\
\hline
\end{tabular}

NEHA: Nurse Education Health Assistants

Table 8: Cases not assigned VIEW scores by system but were captured by Nurse Education Health Assistants coach

\begin{tabular}{lc}
\hline NEHA VIEW score & Frequency, $\boldsymbol{n}$ (\%) \\
\hline A & $161(79.7)$ \\
B & $25(12.38)$ \\
C & $2(0.99)$ \\
E & $14(6.93)$ \\
Total & $202(100)$ \\
\hline
\end{tabular}

NEHA: Nurse Education Health Assistants

Table 9: VIEW scores given by NEHA coach and the doctor to the "not assigned" cases of system $(n=14)$

\begin{tabular}{llccc}
\hline & NEHA coach & \multicolumn{3}{c}{ Doctor } \\
\hline VIEW score & E & A & B & D \\
$\mathrm{n}$ & 14 & 5 & 8 & 1 \\
\hline
\end{tabular}

Table 10: Cases not assigned VIEW scores by system but were captured by doctor

\begin{tabular}{lc}
\hline Doctor VIEW score $(\boldsymbol{n = 8 6 )}$ & Frequency, $\boldsymbol{n}(\mathbf{\%})$ \\
\hline A & $51(59.3)$ \\
B & $30(34.88)$ \\
C & $4(4.65)$ \\
D & $1(1.16)$ \\
Total & $86(100)$ \\
\hline
\end{tabular}

We have introduced unique way to collect data of individuals using VIEW application which can classify individuals according to their severity of risk and it provides easy identification of those individuals who require immediate attention. Moreover, involving NEHA coach and onboard doctors for teleconsultation have provided easy access for the employees to get health-care consultation service. Thus, VIEW system is useful to reduce the burden of health-care ecosystem by multiple levels of screening and filtering.

\section{ConcLusion}

This study put forth valuable insights into COVID-19 risk screening by categorizing the participants depending upon intensity of the risk. The VIEW system developed by BRIOTA technologies was found compatible to detect the risk probability toward COVID-19 infection. The scores given by the system to individuals are either the same or higher as compared to the trained nurses or doctors, ensuring that they are more likely to get the required attention, even if erring slightly on the cautious side. This system can prove useful as a screening tool when access to qualified health-care personnel is not immediately available. It may reduce the existing burden of health-care system and offer health-care solutions to the corporate health-care ecosystem during this crucial episode of pandemic.

\section{Financial support and sponsorship}

This pilot project was conducted based on funding received from the client and carried out by team and partner teams of Briota Technologies Pvt. Ltd. (www.briota.co) from Pune.

\section{Conflicts of interest}

The authors Shardul Joshi, Dr. Gajanan Sakhare, and Aditi Pais are employees of BRIOTA Technologies Private Limited who created the software application. "BRIOTA Technologies Private Limited" is conducting and sponsoring this research. Shardul Joshi and Dr. Gajanan Sakhare are inventors on National Patent application which is pending.

\section{REFERENCES}

1. Chakraborty I, Maity P. COVID-19 outbreak: Migration, effects on society, global environment and prevention. Sci Total Environ 2020;728:138882.

2. Hussain Y, Muhammad K, Umer MF, Omarkhail A, Khan S, Kamran M, et al. Coronavirus disease 2019 in 5 neighboring limited-resource countries: A financial and health threat. Value Health Reg Issues 2020;24:114-6.

3. Anderson RM, Heesterbeek H, Klinkenberg D, Hollingsworth TD. How will country-based mitigation measures influence the course of the COVID-19 epidemic? Lancet 2020;395:931-4.

4. Communities, Schools, Workplaces, and Events. Centers for Disease Control and Prevention; 2020. Available from: https://www.cdc. gov/coronavirus/2019-ncov/community/office-buildings.html. [Last accessed on 2020 Nov 04].

5. Spinazzè A, Cattaneo A, Cavallo DM. COVID-19 Outbreak in Italy: Protecting Worker Health and the Response of the Italian Industrial Hygienists Association. Ann Work Expo Health 2020;64:559-64.

6. Coronavirus Disease (COVID-19): Health and Safety in the Workplace; 2020. Available from: https://www.who.int/news-room/q-a-detail/cor 
onavirus-disease-covid-19-health-and-safety-in-the-workplace. [Last accessed on 2020 Nov 05].

7. World Health Organization. WHO COVID-19 Case Definition, Public Health Surveillance for COVID-19. Available from: https://www. who.int/publications/i/item/WHO-2019-nCoV-Surveillance_Case_ Definition-2020.2. [Last accessed on 2020 Apr18].

8. Azlan AA, Hamzah MR, Sern TJ, Ayub SH, Mohamad E. Public knowledge, attitudes and practices towards COVID-19: A cross-sectional study in Malaysia. PLoS One 2020;15:e0233668.

9. COVID-19-Thermal Screening of Lawyers, Litigants, Scribes at SC: The Hindu; 2020. Available from: https://www.thehindu.com/newsnational/ covid-19-thermal-screening-of-lawyers-litigants-scribes-at-sc/ article31080799.ece. [Last accessed on 2020 Apr 18].

10. Huang C, Wang Y, Li X, Ren L, Zhao J, Hu Y, et al. Clinical features of patients infected with 2019 novel coronavirus in Wuhan, China. Lancet 2020;395:497-506.

11. Magnavita N, Tripepi G, Prinzio RR. Symptoms in health care workers during the COVID-19 epidemic. A cross-sectional survey. Int J Environ Res Public Health 2020;17:1-15.
12. COVID-19 Double Blow for Chronic Disease Patients in India: Study: Times of India; 2020. Available from: https:// timesofindia.indiatimes.com/life-style/health-fitness/health-news/ covid-19-double-blow-for-chronic-disease-patients-in-india-study/ articleshow/78854167.cms. [Last accessed on 2020 Oct 25].

13. CDC. Coronavirus (COVID-19): Symptoms of Coronavirus. Centers for Disease Control and Prevention; 2020. Available from: https:// www.cdc.gov/coronavirus/2019-ncov/symptoms-testing/symptoms. html. [Last accessed on 2020 Apr 18].

14. BCCDC. COVID-19 Vulnerable Populations. British Columbia Centre for Disease Control; 2020. Available from: http://www.bccdc.ca/ health-info/diseases-conditions/covid-19/vulnerable-populations. [Last accessed on 2020 Apr 18].

15. Guan WJ, Liang WH, Zhao Y, Liang HR, Chen ZS, Li YM, et al. Comorbidity and its impact on 1590 patients with COVID-19 in China: A nationwide analysis. Eur Respir J 2020;55:2000547.

16. Sanyaolu A, Okorie C, Marinkovic A, Patidar R, Younis K, Desai P. Comorbidity and its Impact on Patients with COVID-19. SN Compr Clin Med 2020;2:1069-76. 